\title{
"Ceria”
}

Jurnal Pendidikan Anak Usia Dini

ISSN 2301-9905

Volume 11, No. 2, Januari 2020

Fakultas Keguruan dan Ilmu Pendidikan- Universitas Muhammadiyah Tangerang

\section{Penerapan Reinforcement Dalam Mendisiplinkan Anak Usia 5-6 Tahun di TK Islam Kinasih Kecamatan Pinang Tangerang}

\author{
${ }^{1}$ Siti Masruroh, ${ }^{2}$ Nurul Fitria Kumala Dewi \\ 1,2Program Studi Pendidikan Guru Pendidikan Anak Usia Dini Fakultas Keguruan \\ Dan Ilmu Pendidikan Universitas Muhammadiyah Tangerang \\ e-mail :1 sitimasruroh884@gmail.com,2nurulfitriakd@gmail.com
}

\begin{abstract}
Abstrak
Penanaman karakter seperti kedisiplinan diusia prasekolah sangat penting untuk dilakukan. Penanaman karakter disiplin dilakukan melalui pembiasaan sitiap hari selama proses belajar meengajar mencakup ketrampilan hidup, sosial, control diri, patuh pada peraturan. Penelitian ini bertujuan untuk menamkan karakter disiplin pada anak usia dini kususnya anak usia 5-6 tahun melalui penerapan reinforcement selama belajar mengajar di TK Islam Kinasih. Data yang terkumpul melalui metode oservasi, wawancara, dokumentasi dan analisis diskriminatif kualitatif. Hasil dari penelitian bahwa di TK Islam Kinasih telah menerapakan reinforcement dengan adil dan seimbang, telah menggunakan ketrampilan reinforcement dengan bervariasi, menggunakan prinsip-prinsip reinforcement kesabaran, bermakna kehangatan, waktu pemberian reinforcement dengan fleksibel dan menggunakan teknik reinforcement positif, modelling dan token conemy. Hasil analisis data penelitian adalah penerapan reinforcement dapat diterapkan oleh berbagai pihak untuk diterapkan di sokalah oleh guru maupun orang tua di rumah. Jenis kedisiplinan yang diterapkan yaitu di siplin demokratis dan memotivasi anak melalui penerapan reinforcement.
\end{abstract}

Kata kunci : Disiplin, Reinforcement. Anak Usia 5-6 Tahun

\section{Pengantar}

Pendidikan Anak Usia Dini (PAUD) adalah dasar untuk mengembangkan pendidikan pada tahap selanjutnya. Pendidikan Anak Usia Dini penuh tantangan dan permasalah disetiap tahap perkembangannya. Pendidikan anak usia dini mengembangkan semua aspek perkembangan meliputi fisik motorik, kognitif, bahasa, sosial emosional. Sosial anak usia dini masih terbatas lingkungan rumah dan sekolah disinilah fungsi pendididikan anaka usia dini untuk mengenalkan lingkungan yang lebih luas dan menanamkan nilai-nilai karakter baik pada anak seperti disiplin. Tujuan disiplin pada anak usia dini yaitu supaya memberitahukan kepada anak-anak mana yang boleh dilakukan dan mana yang tidak boleh 
dilakukan untuk berprilaku sesui dengan lingkunganya dan mengontrol prilaaku yang tidak diinginkan (Hurlock, 2011).

Pentingnya kedisiplinan supaya anak bisa menyesuaikan diri di lingkungan yang sesuai norma dan budaya dimanpun anak berada. Dengan disipin anak dapat membedakan mana yang benardan mana yang salah sesui dengan norma dan budaya yang beralku. Anak usia 5-6 tahun cenderung melakukan sesuatu hal yang benar karena menghindari hukuman bukan atas dasar kemurahan hati. Anak usia dini juga termotivasi untuk melakukan sesuatu untuk mendapatkan rasa kagum dari teman-temannya belum belum bisa membedakan mana yang benar dan mana yang salah. Maka disinilah pentingya peran orang tua dan guru untuk nanamkn karakter disiplin pada anak sejak dini. Namun nyak orang tua ataupun guru yang alih-alih mendisiplinkan anaknya dengan cara kekerasan. Perlu cara dan pendekatan yang sesuai dengan perkembangan anak sehingga anak merasa senang dan mengerti apa yang diharapkan orangtuana atau gurunya salah satu caranya yaitu dengan reinforcement.

Berkaitan dengan hal kedisiplinan menunjukan bahwa hal tersebut yang menjadi permasalahan di TK Islam Kinasih Kecamatan Pinang Kota Tangerang. Menurut hasil pengamatan masih banyak dijumpai anak yang datang terlambat, mengobrol sendiri pada saat pembelajaran berlangsung, menyela saat mencuci tangan. Hasil wawancara yang dikemuka oleh guru, di TK Islam Kinasih ini sudah menerap reinforcement untuk mendisiplinkan reinforcement yang sesuai dengan anak dan dengan cara yang disukai anak melalui berbagai kegiatan dan rutinitas sehari-hari. Guru menghindari hukuman fisik disini guru menggunakan reinforcement yang mendidik anak supaya lebih bertanggungjawab dan menumbuhkan rasa empati anak terhadap sesama.

Fokus penelitian ini berdasarka latar belakang di atas. Yaitu bagaimana guru TK Islam Kinasih menerapkan reinforcement dalam mendisiplinkan anak usia 5-6 Tahun. Menganalisis bagaimana penggunaan reinfcement dalam mendisiplikan anak usia 5-6 Tahun di TK Islam Kinasih. 
Perumusan masalah dari latar belakang yang di hadapi TK Islam Kinasih antara lain: Bagaimana TK Islam Kinasih menerapkan reinforcement dalam mendisiplinkan anak. Kendala apa saja yang dialami ketika menerapkan reinforcement. Hasil setelah setelah menerapkan reinforcement terhadap kedisiplinan anak.

Adapun tujuan dari penelitian ini adalah mencari tahu reinforcement apa yang diterapkan di TK Islam Kinasih dalam mendisiplinkan anak usia 5-6 tahun. Menganalisis kedala apa saja yang hadapi oleh guru TK Islak Kinasih dalam mendisiplinkan anak. Hasil yang diperoleh dari penerapan reinforcement terhadap kedisiplinan anak usia dini di TK Islam Kinasih.

Anak usia 5 tahun dimana anak sedangdalam masa emas semua informasi terserap dengan sangat cepat. Masa inilah sangat tepat untuk mengajarkan anak tentang karakter disiplin. Orang tua dan guru sangat berpengaruh dalam mengembangkan karakter anak. Melalui pembiasaan disiplin maka anak akan terbiasa berlaku disiplin hingga dewasa kelak. Jadi pengalaman masa sekarang itu akan mempengaruhi anak masa yang akan datang (Freud dalam Koesoema, 2018, h.239).

Disiplin tidak terlepas dari peraturan. Praturan dibuat untuk ditaati oleh semua yang bersangkutan. Mentaati peraturan harus dilskukan dengan sungguh-sungguh dan menyadari apa konsekuensi dan resikonya bagi yang melanggar. Oleh karena itu memerlukan kesadaran untuk dapat melaksanakannya dengan sukarela. Anak usia dini memerlukan pendekatan dalam penyampainya agar tumbuh rasa disiplinnya. Pendekatan secara humanis lebih memberikan perhatian pada nilai isi sebuah disiplin (Koesoema, 2018, h.239). pendekatan yang disesuaikan dengan situasi dan kondisi anak dan menggunakan bahasa yang dapat dimengerti anak. Pada usia ini anak dalam masa bermain sangat cocok bila menggunakan pendekatan melalui bermain sambil belajar disiplin.

Pada usia 5 tahun, anak belum bisa bisa yang benar dan mana yang salah. Anak hanya tahu kalau orang lain senang berarti boleh dilakukan. Orang tua dan guru disini mengenalkan ujuan disiplin disini disiplin supaya anak bisa berprilaku sesuai dengan tuntunan norma yang belaku di masyarakat agar dapat diterima dikelompoknya (Hurlock, 2003). Disiplin 
berasal dari kata "Disiple" yang berati seorang yang belajar dari dirinya sendiri atau suka rela mengikuti pemimpin (Mursid, 2015, h. 81). Disiplin dapat diartikan suatu tindakan yang menunjukan prilaku tertib dan patuh pada berbagai ketentuan dan aturan (Gunawan, 2012, h. 33). Prilaku disiplin juga tidak terkecuali disekolah, karena disekolah merupakan tepat belajar baik secara tertulis maupun secara lisan tujuanya yaitu agar tercapai target pembelajaran.

Disiplin adalah proses bimbingan yang bertujuan menanamkan pola prilaku tertentu, kebiasaan-kebiasaan tertentu untuk membentuk manusia dengan ciri-ciri tertentu (Rosmini, 2011, h. 7). Dari beberapa pengertian diatas disiplin dapat diartikan proses bimbingan yang mengajarkan anak supaya terbentuk karakter serta control diri, berprilaku tertib, patuh terhadap berbagai ketentuan serta peraturan yang berlaku yang dapat diterima oleh masyarakat dilingkunganya dengan kesadaranya sendiri.

Ada beberapa jenis disiplin yang dapat diterapkan dan disesuaikan dengan umur kebutuhan dan usia anak, menurut Hurlck (2011, h. 125) jenis-jenis disipilin antara lain:

a. Disiplin otoriter yaitu disiplin dikendalikan oleh orang tua, guru atau pengasuh merka

b. Disiplin lemah yaitu: Tidak adanya kesepakatan dan kejelasan aturan serta konsekuensi, yang konsisten terhadap aturan-aturan tersebut.

c. Disiplin demokrat yaitu disiplin atas dasar membuat aturan sesuai kesepakatan bersama berdasarkan musyawarah.

Kecederungan orang menggunakan disiplin demokratis. Apapun bentuk disiplin yang akan diterapkan kepada anak sebaiknya mempertimbangkan kebutuhan serta situasi dan kondisi anak. Bila suatu hal itu sangat penting dan membahayakan, orang tua maupun guru boleh menggunakan disiplin otoriter. Beri penjelasan kepada anak alasan dan buat peraturan yang jalas.

Sebagai orang tua atau guru jangan sampai salah dalam menerapkan disiplin terhadap anak. Ada beberapa bentuk disiplin menurut Papalia, Old, Feldman (2010, h. 39). Bentuk bentuk disiplin menurut teknik behavioral berupa penguatan dan hukuman antara lain: 58 
hukuman fisik, kekuatan, ketegasan, induksi, dan withdrawal of love. Disiplin disini mengenalkan anak batasan mana yang benar dan mana yang salah. Orang tua dalam mendisiplinkan anak perlu mengetahui unsur disiplin. Menurut Mursid (2015, h. 82) mengemukaan unsur-unsur yang berkaitan dengan disiplin itu ada 4 antara lain: a) peraturan, b) hukuman, c) penghargaan, d) konsisten.

Unsur-unsur disiplin diatas harus diterapkan bila ingin anak berlaku disiplin. Bila salah satu saja tidak terpenuhi maka anak akan bingung membedakan prilaku apa yang harus dilakukan.

Mengingat pentingnya disiplin guru maupun orangtua harus menanamkannya sejak dini karena menurut Menurut Hurlock (2011, h. 125) tujuan disiplin adalah memberitahukan kepada anak-anak prilaku mana yang baik dan mana yang buruk, dan mendorongnya untuk berprilaku sesuai dengan standar-standar sosial serta mengotrol prilakku yang tidak sesuai. Supaya anak dapat diterima oleh kelompoknya dan dapat menyesuaikan diri dengan lingkungan atau kelompok dimana anak itu tinggal.

Anak belum mengenal salah dan benar. Tugas orang tua dalam menanamkan nilai disipilin kepada anak sejak dini. Menurut Cooper dkk (2009, h. 358) Usia 5-6 tahun anak cenderung melakukaan hal yang benar utuk menghindar hukuman bukan atas dasar kebaikan atau kemurahan hati. Ia juga termotivasi untuk mendapatkan persetujuan oranng lain serta rasa kagum dari teman-temanya, ia juga dapat membedakan peraturan yang bersifat rutin dan peraturan yang mengundang nilai moral. Jadi anak hanya ingin cari perhatian dari orangorang disekitarnya.

Salah satu cara agar prilaku yang diharapkan meningkatkan dan melemahkan prilakuyang tidak diharapkan melalui reinforcement. Menutut Marno (2010, h. 132) reinforecement adalah respon positif yang dilakukan guru atas prilaku positif yang dicapai anak dalam proses belajarnya, bertujuan untuk mempertahankan dan meningkatkan prilaku tersebut. Zainal (2012, h. 77) mengungkapkan reinforcement adalah respon terhadap suatu tingkah laku positif yang dapat meningkatkan kemungkinan berulangnya kembali tingkah laku tersebut. 
Menurut Skinner dalam Muklas (2015, h. 59) reinforcement adalah stimulus yang meningkatkan kemungkinan timbulnya sejumlah respon tertentu.

Jadi menurut kajian beberapa teori diatas dapat disimpulkan bahwa reinforcement atau penguatan adalah dorongan respon yang dilakukan untuk meningkatkan kemungkinan timbulnya repon atas conditioning atau prilaku agar prilaku tersebut meningkat atau terulangnya prilaku positif tertentu dan mengontrol prilaku yang tidak diinginkan.

Orang tua dan guru menginginkan anak didiknya menjadi anak yang mempunyai karakter baik seperti disiplin. Tujuan pemberian reinforcement menurut Marno (2010, h. 133). Pemberian reinforcement atau penguatan bila dilakukan dengan cara dan prisip yang benar mengefektifkan tujuan penguaatan atau prilaku yang diharapkan adapun tujuan dari pemberian reinfoecement atau pennguatan yait: a) Meningkatkam perhatian, b) Membangkitkan dan memelihara dan meningkatkan motivasi, c) Mengerah pada pengembangan berfikir kearah devergen, d) Mengatur dan mengarahkan keproses belajar, e) Mengendalikan serta memokasi tingkah laku yang kurang positif kearah tingkah laku yang produktif.

Setiap respon yang diikuti oleh reward ini bekerja sebagai reinforcement stimuli akan cenderung di ulangi. Reward atau reinforcement stimuli akan meningkatkan kecepatan atau rute teerjadi respon. Kecepatan atau tingkatan seberapa besar prilaku itu diulang atau ditingkatkan tergantung seberapa besar hadiah atau stimulus yang diterima. Menurut Marno (2010, h. 134) prinsip-prinsip reinforcement antara lain: a) kehangatan, b) Antusiasme, c) Bermakna d) Menghin dari respon negatif.

Menurut Skinner dalam Bimo (2010, h. 81) reinforcement dibagi menjadi 2 yaitu: a) Reinforcement Positif: adalah apabila dilakukan akan meningkatkan probabilitas positif. Bisa beruapa hadiah, sentuhan, pemberian pujian, pemberian kegiatan yangmenyenangkan, senyuman, tos. b) Reinforcement negatif adalah sesuatu yang apabila dalam suatu situasi akan meningkatkan probabilitas respon. Bisa berupa hukuman, pemberhentian vasilitas atau kegiatan yang disenangi. 
Pemberian reinforcement juga harus memperhaatikan beberapa komponen yang perlu dipahami dan dikuasai. Supaya dapat memberikan reinforcement secara bijaksana dan sistematik. Berikut ini beberapa komponen ketramplan memberikan reinforcement yaitu: a) Pengutataan verbal, b) Penguatan gestural, c) Pendekatan, d) sentuhan, e) Pemberian kegiatan yang menyenangkan, f) Berupa simbol atau hadiah

Pemberian reinforcement memerlukan teknik yang sesui. Menurut Laksamana dalam Lubis (2014, h, 172) membagi teknik terapi behavioristik menjadi 2 bagian yaitu: teknik tingkah laku umum dan teknik spesifik.

a. Teknik Tingkah Laku Umum 1). Schendule (mengulang). 2) Sheping (bertahap). 3). (Ekstingsi)

b. Teknik Spesifik 1) Disentisasi digunakan untuk prilaku yang tidak konsisten yaitu dengan cara menggambarkan perasaannya. 2) Pelatihan asertivitas yaitu

dengan bermai peran. 3) Time out yaitu digunakan apabila tingkah laku tidak sesuai harapan maka dipisahkan dari penguatan positif.

Bagaimana penggunaan reinforcement dan kapan sebaiknya reinforcement itu diberikan. Berdasarkan teori behavior yang dari Skinner dalam Djali (2014, h. 90) dibagi menjadi 5 cara yaitu a) fixed ratio schendule (diberikan setelah terjadinya respon) b) Variable ratio schendule. (diberikan setelah terjadinya rata-rata respon) c) Fixed internal schendule. (berdasarkan waktu) d) Tetap diantara reinforcement. e) Variabel interval schendule (diberiakan berdasarkan respon yang pertama setelah melakukan kesalahan.

\section{Metode}

Berdasarkan jenis perlakuan yang dibuat dalam penelitian ini, maka penulis menggunakan penelitian kualitatif, artinya data yang diperoleh bukan berupa angka-angka melainkan berupa naskah wawancara, laporan dokuman pribadi, catatan memo dan dokumen lainya. Menurut Sugiono (2013, h. 15) metode kualitatif adalah bahwa metode tersebut dapat 
digunakan untuk mendapatkan data yang mendalam. Sumber lokasi pada penelitian ini bertempat di TK Islam Kinasih. Jln. Matahari Rt 003/04 No.27 Sudirman Pinang 15145 Kota Tangerang.

Subyek dalam penelitian ini adalah guru TK Islam Kinasih, jenis data yang dikumpulkan dalam penelitian ini adalah: a) Kata-kata atau Tindakan b) foto (data skunder dan data primer). c) vidio.

Teknik pengumpulan data merupakan hal terpenting dalam sebuah penelitian, dalam penelitian ini peneliti menggunakan tiga jenis teknik pengumpulan data yaitu: a) Metode observasi. b) Wawancara. c) sumber target. d) dokumentasi.

Dalam menganalisis data peneliti menggunakan analisis data model Miles dan Hamberman dalam Sugiono (2016, h. 244) sebagai berikut:

1. Reduksi data (Data Reduktion)

2. Penyajian data (Display Data)

3. Penarikan kesimpulan (verification)

a) Keabsahan Data (Obyektivitas, Kesahihan internal, Tringulasi). b) Kesahihan eksternal. c) Keterandalan

\section{Hasil dan Pembahasan}

Berdsarkan wawancara para guru dan hasil observasi hasil penelitian di TK Islam Kinasih peneliti menemukan antara lain:

1. Subyek (guru) sudah berpengalaman dalam belajar mengajar itu terbukti obyek mengajar lebih dari dari 5 tahun dan telah mengikurti berbagai pelatihan.

2. Guru TK Islam Kinasih sebelum menlakukan kegiatan terlebih dahulu membuat kesepakatan bersama. 
3. Guru TK Islam Kinasih menggunakan berbagai teknik seperti modelling, pemberian penguatan positif, tokenemy. Token konemy adalah teknik yaitu dengan mengumpulkan bintang yang dapat ditukar dengan hadiah

4. Sedang reinforcement negatif berdasarkan wawancara dan observasi guru menggunakan teknik time out untuk menyeterilkan lingkungan dan memanggil anak dengan lagu sambil membaca istighfar, mengingatkan peraturan. pembiasaan sehari-hari.

5. Guru TK Islam Kinasih memiliki ketrampilan dalam menggunakan reinforcement bervariasi seperti gestural, verbal, pendekatan, sentuhan, pemberian kegiatan dan pemberian hadiah.

6. Guru Menggunakan prinsip reinforcement dengan penuh kehangatan, bermakna, antusias, menghindari respon negatif dan penuh kesabaran di setiap kegiatan.

7. Hasilnya anak lebih gembira, bersemangat dalam belajar dan lebih disiplin dalam mengikuti pembelajaran, dan tujuan pembelajaran akan tercapai.

8. Kendala yang dialami oleh guru TK Islam Kinasih yaitu, perbedaan peraturan antara di rumah dan disekolah, waktu yang terbatas disekolah, dan bermacam- macam karakter anak didik

Untuk meminimalisir kendala yang ada, yang dilakukan TK Islam Kinasih melakukan antara lain:

a. Membuat buku penghubung

b. Mengadakan pertemuan walimurid secara rutin

c. Mengomunikasikan permasalahan apa yang dialami anak disekolah dan bagaimana di rumah dengan wali murid

Salah satu cara yang tepat untuk menanamkan kedisiplinan anak dengan reinforcement teknik modelling mengingat anak usai 5-6 tahun suka menirukan orang lain (Santuso, 2011) tanpa sadar anak akan menirukan apa yang anak dengar lihat dan rasakan. Melalui prilaku guru secara langsung anak akan melihatdan menirukan. Buhungan baik dan harmonis 
antara guru dan anak akan mempengaruhi prilakau anak. Bila guru terbiasa berprilaku disiplin tanpa disadari anak akan mengikutitnya. Bisa juga lewat cerita, lagu-lagu, menoton vidio yang behubungan dengan kedisiplinan. Untuk menunjang kedisiplinan anak perlunya kerjasama antar senua anggota sekolah baik guru, setaf sekolah maupun walimurid dan didukung dengan fasilitas yang memadai yang ada disekolah, baik sarana dan prasarana, yang paling penting adalah dilakukan dengan konsisten secara adil dan terbuka atau demokratis supaya dapat mencapai tujuan pembelajaran.

\section{Kesimpulan}

TK Islam Kinasih ini masih dijumpai anak yang terlambat datang ke sekolah, berebut mecuci tangan, berbicang sendiri saat pembelajaran, jalan-jalan saat berkumpul mlingkar. Peneliti tergelitijk untuk meneliti di TK Islam kinasih ini karena cara guru menangani anak yang kurang disiplin dengan menggunakan reinforcement yang menyenangkan sehingga anak mengerti. Disiplin dapat diartikan proses bimbingan yang mengajarkan anak supaya terbentuk karakter serta control diri, berprilaku tertib, patuh terhadap berbagai ketentuan serta peraturan yang berlaku yang dapat diterima oleh masyarakat dilingkunganya dengan kesadaranya sendiri.

Reinforcement atau penguatan adalah dorongan respon yang dilakukan untuk meningkatkan kemungkinan timbulnya repon atas conditioning atau prilaku agar prilaku tersebut meningkat atau terulangnya prilaku positif tertentu dan mengontrol prilaku yang tidak diinginkan.

Penelitian ini menggunakan penelitian kualitatif diskriminatif yaitu data diperoleh dari hasil observasi, wawancara dan dokumentasi. Hasil peenelitian di TK Islam Kinasih yaitu guru TK Islam Kinasih telah memiliki pengalaman mengajar yang cukup lama yaitu lebih dari 5 tahun dan telah mmengikuti berbagai pelatihan sehingga pengetahuan mereka 
tentang cara mendisiplinkan melalui reinforcement telah diterapkan. TK Islam Kinasih telah menerapkan sebagian besar ketrampilan pemberian reinforcement dengan berbagai teknik antara lain, modelling, pemberian reinforcemen positif dan token konemy. Hasilnya setelah diberikan reinforcement anak menjadi lebih giat belaajar, gembira, dan termotivasi, serta lebih disiplin. Kendala yang dialami oleh guru TK Islam kinasih dalam pemberian reinforcement yaitu karena karakter anak yang berfariasi sehingga berbeda pula penangannya, waktu disekolah yang terbatas, dan perbedaan peraturan antara disekolah dan di rumah. reinforcement dilkukan dengan adil sesuai kemampuan anak.

\section{Daftar Acuan}

Arifin Zainal. (2010). “Evaluasi Pembelajaran". Bandung: PT Remaja Rosdakarya.

Cooper Crol, halsey Claire, Laurent Su, sulivan Karen. (2019). “Ensilkopedia Perkembangan Anak" Erlangga.

Gunawan Heri. (2012). "Pendidikan Karakter Konsep dan implementasi”. Bandung: Alfabeta.

Hurlock B Elizabeth. (2010). "Psikologi Perkembangan” Jakarta: Erlangga. Koesoema Doni. (2018). “Pendidikan Karakter" Jakarta: PT Grasindo

Koesoema Doni. (2018). “Pendidikan Karakter" Jakarta: PT Grasindo

Kusuma Dharma, Trinata Cepi, Permana Johar. (2013)," Pendidikan Karakter", Bandung: PT Remaja Rosdakarya. Marno, Idris. (2010). "Strategi dan Metode Pengajaran" Jogjakarta: Ar-Ruzz Media.

Lubis Lumangga Namora. (2013). "Memahami Dasar-Dasar Konseling dalam Teori dan Praktek". Rawamangun Jakarta: PT Kharisma Putra Utama.

Marno, Idris. (2010). “Strategi dan Metode Pengajaran” Jogjakarta: Ar-Ruzz Media.

Minarno Eko. (2010). "Pengantar Psikologi Umum". Jakarta: PT Rajagrafindo Persada. Papalia E Diane, Old Wendkos Selly (2010), Feldman Duskin Ruth, "Huma Development" Jakarta: Kencana Prenada Media Group. 
Purwanto Ngalim. (2007), "Ilmu Pendidikan Teoretis dan praktis" Bandung: PT Remaja Rosidakarya. Putra Nusa, Fil S, Dwilestari Ninin. (2012)." Penelitian Kualitatif Pendidikan Anak Usia Dini". Jakarta: PT Rajagrafindo persada.

Shochib Moh. (2014). "Pola Asuh Orang Tua Dalam Membantu Anak untuk Mengembangkan Disiplin Diri". Jakarta: PT Rineka cipta.

Susanto Ahmad. (2011). "Perkembangan Anak Usia Dini" Jakarta: Prenada Media Group.

Winkel dan Hastuti Sri. (2010). “Bimbingan dan Konseling di Insititusi Pendidikan". Yokyakarta: PT Grasindo.

Yusuf Syamsu. (2012). "Psikologi Perkembangan Anak dan Remaja". Bandung: PT Remaja Rosdakarya 